\title{
Совместное заседание ОАО "РЖД" и Секции № 9 МРГ при коллегии ВПК РФ
}

\author{
Ю. Ковалевский
}

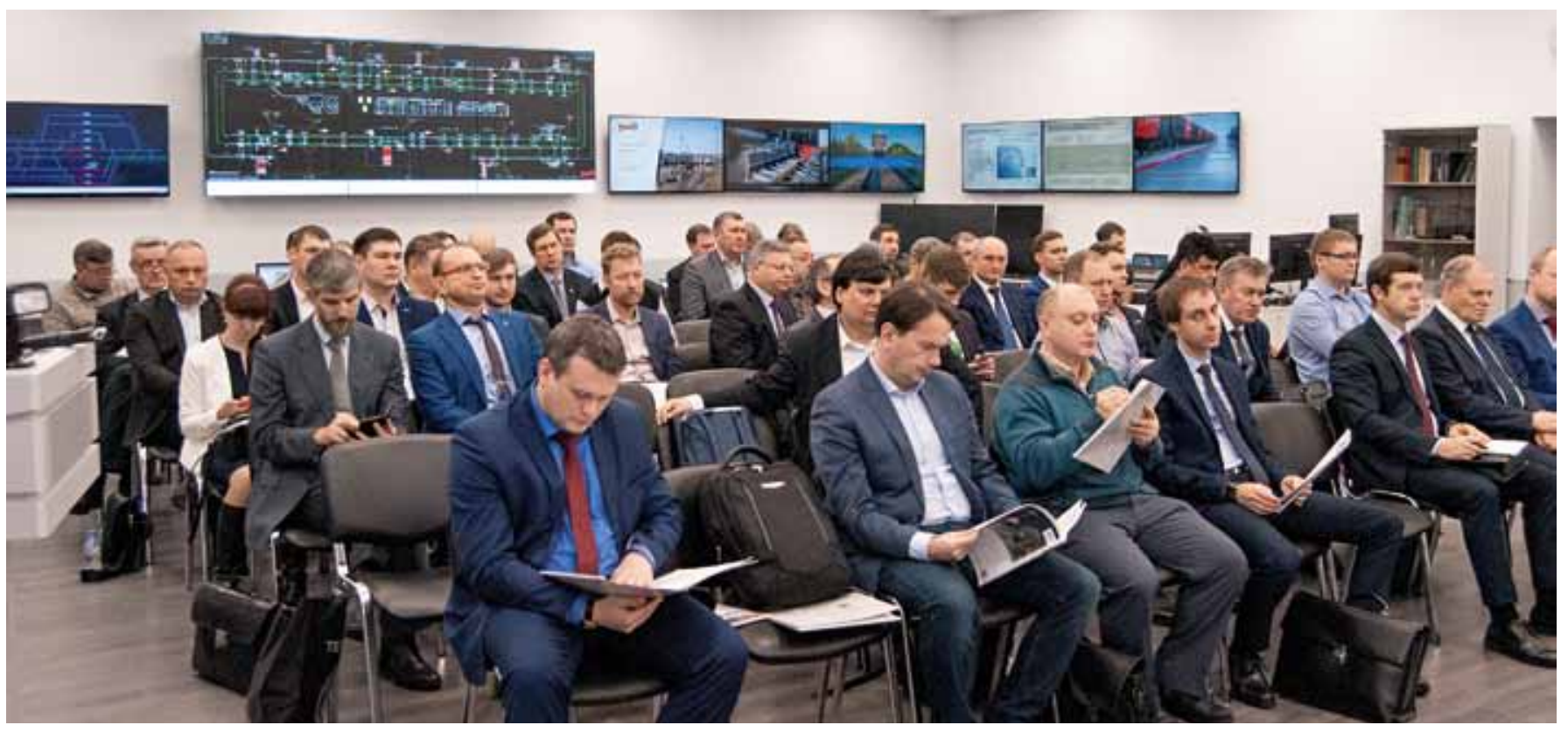

5 декабря 2019 года в Москве на площадке АО «НИИАС" - головного института отрасли железнодорожного транспорта по созданию комплексов и систем обеспечения безопасности движения, управления движением, геоинформационного обеспечения, мониторинга состояния подвижного состава и инфраструктуры железных дорог - прошло совместное заседание ОАО "РЖД" и Секции № 9 по участию малого и среднего бизнеса в разработке и производстве электронной компонентной базы Межведомственной рабочей группы (МРГ) при коллегии Военно-промышленной комиссии Российской Федерации (ВПК РФ). На заседании обсуждались вопросы обеспечения импортонезависимости в области радиоэлектронной аппаратуры, аппаратнопрограммных систем и их компонентов, предназначенных для применения в железнодорожном транспорте, и возможного участия в решении этой задачи малых и средних предприятий, работающих в сфере электроники и радиоэлектроники.

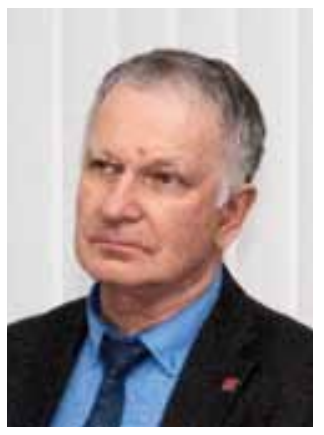

Мероприятие открыл первый заместитель генерального директора АО "НИИАС" Е.Н.Розенберг. В своем приветственном слове он отметил, что железнодорожный транспорт представляет собой гражданскую структуру, в которой применяются самые современные технологии, подчас не

уступающие оборонным. Он указал на то, что заместителем председателя коллегии ВПК РФ О.И. Бочкарёвым в рамках данной рабочей группы поставлены задачи, требующие активной работы по импортозамещению. Однако импортозамещение рассматривать просто как замену импортных компонентов нельзя. Это целое направление, которое должно иметь целью обеспечение импортонезависимости во всех аспектах: как на уровне аппаратуры и программного обеспечения, так и на уровне компонентов. 
Также с приветственным словом Выступил директор АНО "Институт стратегий развития", руководитель Секции № 9 П.А.Верник. Он выразил благодарность ОАО «РЖД" в целом и лично Е.Н. Розенбергу за начатый диалог и кратко описал условия, в которых такое общение становится особо актуаль-

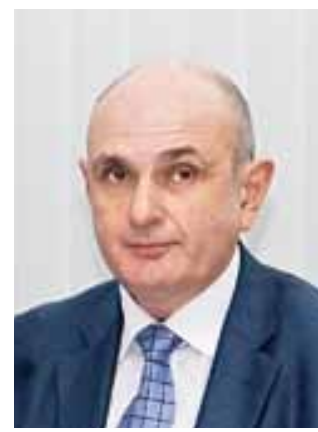
ным. По его словам, задача им-

портозамещения уже переросла в задачу импортоопережения, и для ее решения необходимо обеспечение серийности продукции, которое, в свою очередь, требует рынков сбыта. Эти рынки могут быть обеспечены гражданским применением, и железнодорожный транспорт видится одним из первоочередных потребителей, который может сформировать спрос на высокотехнологичную продукцию, способствуя развитию передовых отечественных технологий, в том числе в рамках диверсификации ОПК.

После приветственных слов были представлены доклады по теме мероприятия, первым из которых стал доклад Е. Н. Розенберга на тему «Подходы к импортозамещению с учетом обеспечения информационной и функциональной безопасности".

Докладчик еще раз подчеркнул, что под целью импортозамещения необходимо понимать импортонезависимость: важно не заменить отдельные компоненты или блоки на отечественные аналоги, а обеспечить независимость от иностранного поставщика.

С позиций ОАО «РЖД", импортонезависимость ВКлючает три составляющие. Первоочередная из них - технологическая и функциональная. По словам докладчика, на этом уровне в ОАО “РЖД" независимость обеспечена; более того, во многих случаях российские технологии превосходят зарубежные.

Вторая составляющая - независимость алгоритмическая и в плане ПО. Она также обеспечена в ОАО «РЖД»: алгоритмы и ПО создаются российскими программистами. При этом программисты постоянно поддерживают разрабатываемые системы, закрепляются за ними, а не нанимаются лишь для решения отдельной задачи.

Третья составляющая - ЭКБ и технологии производства. Как отметил Е.Н. Розенберг, к решению задачи независимости на этом уровне невозможно приступать, не обеспечив первую и вторую составляющую.

Далее докладчиком был приведен ряд примеров крупных проектов, реализованных в недавнее время и показывающих уровень применения российских технологий в ОАО «РЖД".
На примере комплекса автоматизированного управления движением поездов Московского центрального кольца Е. Н. Розенберг показал, как решаются задачи импортонезависимости на различных уровнях. Если на нижнем уровне - преимущественно напольного и бортового оборудования - и в аппаратуре, и в ПО российские инновационные технологии составляют 100\%, то на верхнем уровне, который представлен интеллектуальными системами, рассчитывающими графики движения и в реальном масштабе времени передающими их на линию, несмотря на то, что эта доля также приближается к 100\%, еще имеются нерешенные задачи в отношении как аппаратуры, так и системного ПО.

Также было продемонстрировано соотношение применяемого российского и зарубежного оборудования в системах связи. В большинстве систем отечественное оборудование превалирует над импортным, однако в тех видах связи, где существует зависимость от общих информационных технологий, прежде всего в ІР-транспорте, доля аппаратуры российского производства остается низкой.

Обеспечение импортонезависимости в ИТ-сфере докладчик разделил на три этапа. В качестве текущей задачи было отмечено импортозамещение прикладного ПО. Второй этап, срок завершения которого был обозначен как 2023-2025 годы, направлен на создание программных платформ. Далее предполагается поэтапное достижение импортонезависимости в области аппаратных платформ и компонентной базы. При этом до 2025 года планируется перейти на закупку оборудования для информатизации только российской сборки (см. рисунок).

Докладчик привел примеры предприятий ОПК, которые разрабатывают и производят аппаратуру для Р»Д в рамках диверсификации, а также применяемых на железнодорожном транспорте операционных систем российской разработки. Среди отечественных производителей микроконтроллеров и микропроцессоров были выделены «ПКК Миландр" и МЦСТ, с которыми у АО «НИИАС" имеется наибольший опыт взаимодействия. При этом процессоры "ПКК Миландр" находят применение в более массовом сегменте низкофункциональной аппаратуры, в частности - бортовой, а "Эльбрусы» разработки МЦСТ - в более сложных системах, таких как АРМ, системы диспетчерского управления и т.д.

Большое внимание докладчик уделил вопросам кибербезопасности, отметив, что в железнодорожном транспорте, как и в таких отраслях, какатомная или энергетическая, негативные последствия кибератаки могут возникнуть незамедлительно и привести к серьезным последствиям. Е. Н. Розенберг рассказал, что в институте создан специализированный центр кибербезопасности, разработаны нормативные документы, методики по проверке, правила классификации. 


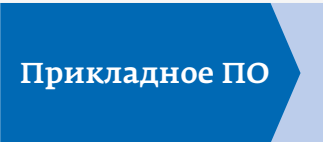

На 100\% производится в Российской Федерации.

Использует так называемое Стандартное ПО:

суБД, ОС, прикладные платформы - SAP, 1C

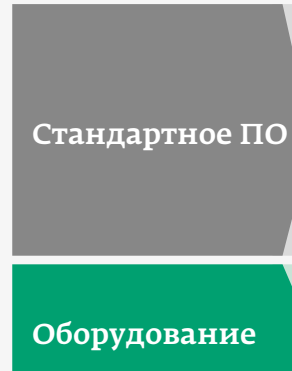

\section{Российское}

Целесообразно при новых закупках

Свободно распространяемое

Кроме снижения импортозависимости, решает задачу

минимизации расходов

\section{Иностранное}

Используется в ранее разработанных автоматизированных системах

Переход до 2025 года к закупке оборудования только российской сборки

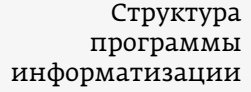

01 информатизации

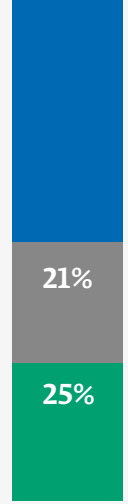

Задачи импортозамещения в области информатизации в ОАО «РЖД"

Приводя примеры перспективных проектов ОАО «РЖД» с импортозамещенной ЭКБ и отечественным ПО (см. табл.), докладчик подчеркнул, что центром кибербезопасности АО «НИИАС" постоянно проводится экспертный анализ вновь разрабатываемых устройств и узлов.

В заключение доклада были представлены предложения по государственной поддержке импортозамещения, включая:

- государственное стимулирование производства или государственные гарантии;

- формирование общего заказа по различным отраслям народного хозяйства для обеспечения низкой цены на процессоры;

- создание списка рекомендованных к использованию отечественных микросхем - перечня главного конструктора;

Перспективные проекты ОАО "РЖД" с импортозамещенной элементной базой и отечественным программным обеспечением

\begin{tabular}{|c|c|c|}
\hline & Проекты & $\begin{array}{c}\text { Срок } \\
\text { реализации, } \\
\text { год }\end{array}$ \\
\hline 1 & $\begin{array}{l}\text { Перспективная бортовая система } \\
\text { обеспечения безопасности для } \\
\text { высокоскоростного движения }\end{array}$ & 2019 \\
\hline 2 & Системы поездной радиосвязи & 2019 \\
\hline 3 & Система АБ & 2020 \\
\hline 4 & Система ДЦ & 2021 \\
\hline 5 & Система МПц & 2021 \\
\hline 6 & $\begin{array}{l}\text { Автономные периферийные } \\
\text { контроллеры }\end{array}$ & 2020 \\
\hline 7 & $\begin{array}{l}\text { Дальнейший перевод существую- } \\
\text { щей техники на отечественные } \\
\text { вычислительные элементы }\end{array}$ & \\
\hline
\end{tabular}

- создание кристального производства на территории РФ;

- материальную поддержку со стороны государства для проведения дорогостоящей сертификации операционных систем.

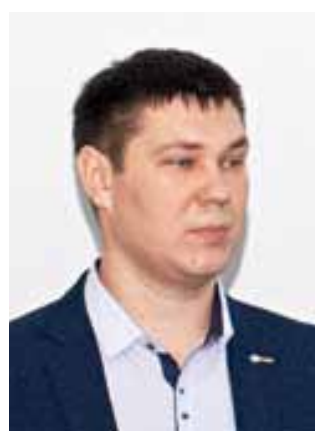

Блок докладов с предложениями разработчиков и производителей ЭКБ по взаимодействию с предприятиями ОАО «РЖД" начался с презентации А. В. Галанова, начальника бюро отдела маркетинга ОАО "Элеконд", который познакомил присутствующих с продукцией предприятия в области электролитических алюминиевых и танталовых конденсаторов, в том числе для поверхностного монтажа. Было рассказано про ряд новинок и приведены примеры применений данных изделий. Кроме того, докладчик рассказал о направлении суперконденсаторов, которые могут найти применение как на подвижном составе, так и в системах управления.

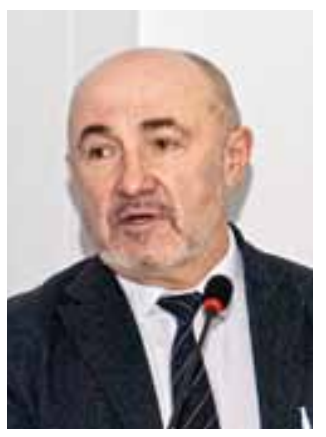

И. К. Корепанов, коммерческий директор АО "Ангстрем", в начале своего доклада подчеркнул, что представляемое им предприятие, обладая полным циклом от кристального производства до готовых компонентов и модулей, способно обеспечить высокий уровень импортонезависимости. Доклад был посвящен силовой ЭКБ АО «Ангстрем», ВКлючающей MOSFET, IGBT-транзисторы и модули, FRD-диоды, а также 
управляющие схемы, драйверы и схемы контроля. Также докладчик рассказал о IGBT-модулях предприятия, способных выдерживать режим КЗ длительностью 40 мкс, что в 4 раза превышает соответствующий показатель у зарубежных аналогов, и на 20-30\% энергоциклов больше, чем импортные изделия. Также АО «Ангстрем» запускает в производство первый отечественный прижимной IGBТ-модуль, который уже прошел ряд испытаний и цена которого будет значительно ниже импортного аналога.

\section{В.А.Косевской, директор по} производству АО «НПЦ СпецЭлектронСистемы" (НПЦ СЭС), представил доклад на тему «Керамические системы в корпусе (микросборки) для управления силовыми исполнительными механизмами в условиях тяжелой эксплуатации". Он отметил, что ввиду возрастающей сложности

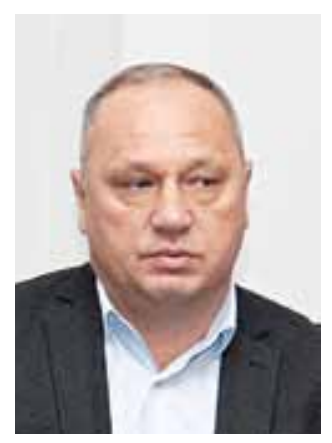
ЭКБ, ее основой в будущем смогут

стать микросборки, и привел ряд преимуществ LTCC-керамики как основы таких микросборок. Докладчик познакомил присутствующих с возможностями НПЦ СЭС по разработке конструкций и изготовлению СвК на основе LTCC и привел пример реального проекта, выполненного на предприятии. В качестве основного перспективного применения рассматриваемой технологии В.А. Косевской отметил возможность создания сложных СвК за короткие сроки на основе унифицированных конструкций.

\section{С.В.Лебедев, директор ди-} зайн-центра ниу Миэт, представил вниманию присутствующих текущие результаты поисковой НИР, которая проводится НИУ МИЭТ в сотрудничестве с Южным федеральным университетом и компанией "Валтар". Индустриальным партнером является ЗНТЦ. Данная работа направлена на создание

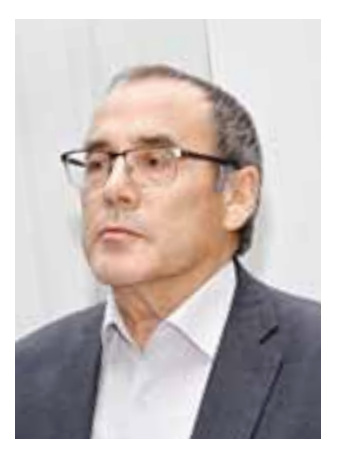
подшипников со встроенной системой контроля таких параметров, как скорость вращения, угловое положение, вибрация и температура, полностью на отечественной ЭКБ. При применении такого подшипника, например, в буксах колесных пар можно обеспечить постоянный мониторинг состояния как самого подшипника, так и колесной пары в целом. В системе, в частности, применяются специально разработанные малошумящие усилители и 16-разрядный АЦП с частотой выборки 500 кГц. Планируется, что система будет поставлена на производство в 2020 году.
М.С.Пискарёв, заместитель генерального директора по маркетингу и продажам микросхем АО НПц "Элвис", посвятил свой доклад процессорам "Мультикор", выпускаемым компанией. Подчеркнув ключевую роль микропроцессоров в обеспечении кибербезопасности, докладчик рассказал о том, как эта

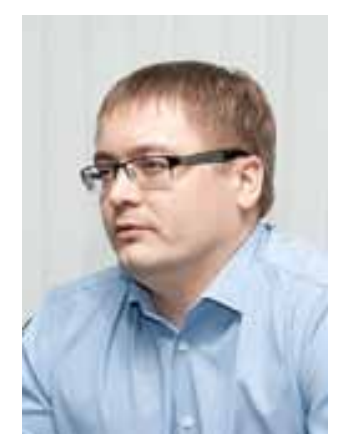
задача решается внутри систем на кристалле "Мультикор". Также в докладе был представлен план развития процессоров "Мультикор»: микроконтроллеры, встраиваемые и серверные процессоры с поддержкой нейросетей, приведены характеристики процессора 1892ВМ14я и процессорных модулей «Салют». Кроме того, М. С. Пискарёв рассказал о применяемых в процессорах "Мультикор» навигационных ядрах глОНАCC/GPS/Beidou/Galileo и привел примеры аппаратуры, разработанной на основе данных процессоров для АО «РЖД".

Тему микропроцессоров продолжил А.А. Огурцов, заместитель генерального директора по коммерческим вопросам AO "Байкал Электроникс". Он сообщил, что за полтора месяца до момента проведения мероприятия был выпущен новый микропроцессор "Байкал-М» с восемью ядрами архитектуры ARM

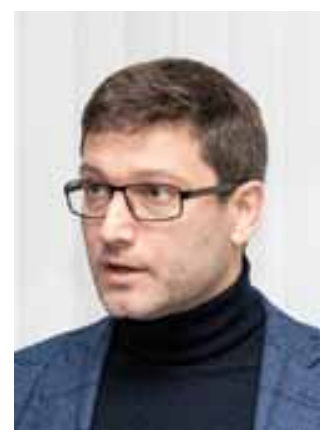
и тактовой частотой 1,5 ГГц, который, в отличие от более ранней разработки, "Байкал-Т», предназначен для более крупных систем, таких как настольные ПК, моноблоки, мини-серверы и т. п. Процессор проходит тестирование у партнеров компании, занимающихся разработкой аппаратуры. Следующая, еще более мощная, разработка, которая, как предполагается, увидит свет в конце 2020 года, - микропроцессор "Байкал-S», предназначенный для применения в серверах, системах хранения данных, суперкомпьютерах.

Также микропроцессорной тематике был посвящен доклад А.э. Мохнаткина, заместителя генерального директора зАО НТЦ "Модуль", при этом докладчик сделал особый акцент на решениях для систем искусственного интеллекта (ИИ), в частности для работы с глубокими сверточными нейросетями,

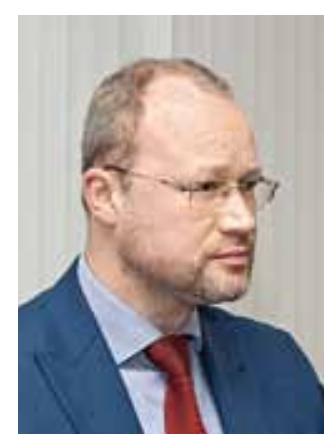


таких как процессор 1879Вм8я. По словам А. Э. Мохнаткина, ЗАО НТЦ "Модуль» является единственной компанией, которая предлагает интегрированное комплексное решение для разработчиков программных комплексов в области ИИ, позволяющее создавать системы полностью на отечественном аппаратном и программном обеспечении. Одной из областей применения таких систем на железнодорожном транспорте может быть распознавание видеоинформации. Кроме того, докладчик рассказал о навигационных модулях компании и о ее опыте в создании бортовой аппаратуры, что также могло бы заинтересовать ОАО «РЖД».

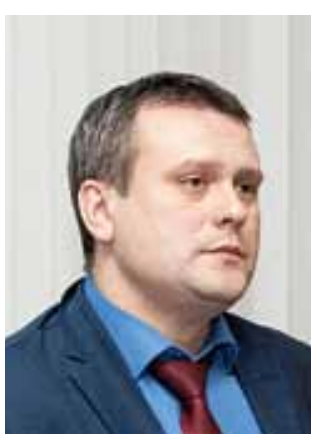

А. А. Меньшиков, заместитель генерального директора по ниОКР АО "НПФ "Микран", рассказал о компетенциях и технологических возможностях компании, в томчисле о собственном дизайн-центре, а также фабрике СВч-МИс на технологиях GaAs и GaN. В качестве потенциальныхнаправлений сотрудничества с ОАО «РЖД" были предложены, в частности, решения для спутниковой связи с подвижным составом, а также концепция "Умный переезд" для обеспечения безопасности железнодорожных переездов на основе радиолокационного сенсора MRS-2000 собственной разработки и производства компании.

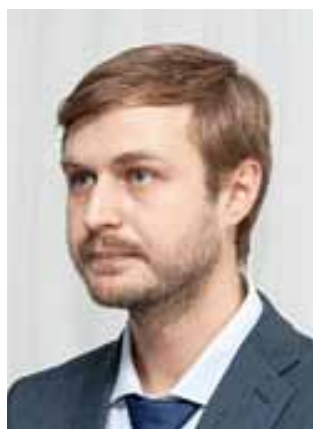

Представитель АО «НПП «Цифровые решения" В.М.Колосов познакомил присутствующих с брокерами сетевых пакетов DS Integrity - одним из устройств разработки компании, применение которого могло бы способствовать обеспечению кибербезопасности в ИТ-инфраструктуре, в том числежелезнодорожного транспорта, а также снизить уровень зависимости от импорта в области передачи данных. Брокеры DS Integrity имеют интерфейсы 10G/40G/100G Ethernet, обладают пропускной способностью до 1,2 Тбит / с на 1U и способны выполнять обработку вложенных заголовков и модификацию трафика на полной скорости. По словам докладчика, данные изделия в определенных аспектах превосходят зарубежные аналоги.

В. А. Бородин, заместитель генерального директора по развитию ФГУп ЭЗАН, посвятил свой доклад преимущественно проблеме обеспечения производства ЭКБ отечественными материалами. Отметив, что материалы играют

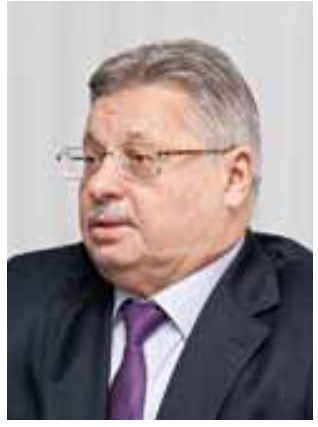

важную роль в технологической независимости, он рассказал о разработанных предприятием установках выращивания монокристаллов SiC - перспективного материала для силовой ЭКБ. Докладчик предложил синхронизировать планы развития с производителями IGBT-транзисторов и модулей, а также других силовых компонентов в интересах РжД для возможности отработки и внедрения отечественной технологии выращивания кристаллов.

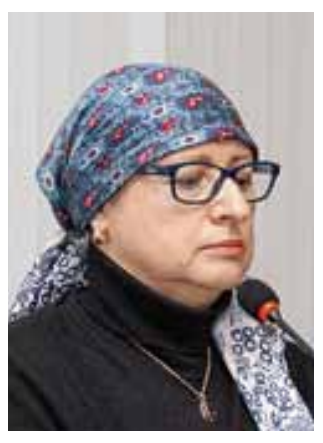

Советник генерального директора АО "ЗИТЦ" А.Н.Михайлова рассказала о направлениях работы компании, которая обладает всеми необходимыми ресурсами для выполнения полного цикла разработки изделий электронной техники от формирования технического задания до постановки на серийное производство, и привела примеры разработок, показывающих опыт АО «зИТЦ» в этой сфере.

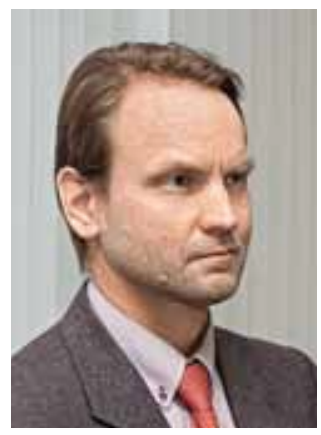

Исполнительный директор ООО "РАМЭМС" Д. М. Урманов, рассказывая о новом направлении деятельности ООО "Совтест ATE» - Sovtest Medica, привел сведения о двух продуктах миниатюрном беспроводном суточном мониторе ЭКГ по Холтеру HOLTERLIVE и суточном мониторе артериального давления TONOLIVE. Также докладчик рассказал о других решениях ООО «Совтест АТЕ», которые могли бы заинтересовать ОАО «РЖД» - системе мониторинга инженерных конструкций на основе протокола LoRa и автономных электрогенераторных установках.

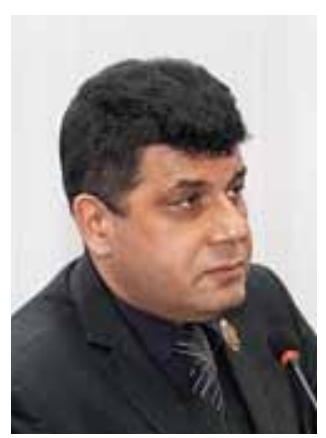

А.С.Шалумов, генеральный директор ООО "НИИ "АСОникА", представил вниманию участников мероприятия доклад на тему «Применение инструментов и возможностей численного (компьютерного) моделирования в системе АСОНИКА для проведения виртуальных испытаний железнодорожной электронной 
техники с целью последующей сертификации продукции».

Главный специалист по лазерному оборудованию Группы компаний «Лазеры и аппаратура" К. Э. Мазуров в своем докладе привел сведения о лазерном технологическом оборудовании собственного производства, включающего станки для лазерной микрообработки, маркировки и гравировки, резки, сварки, пятикоординат-

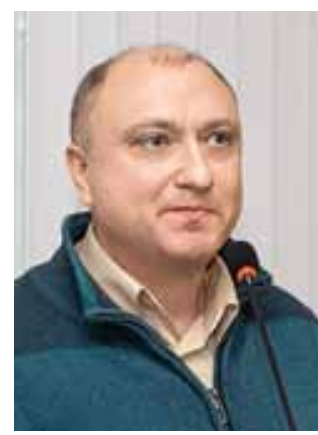
ной прецизионной обработки ответственных изделий, подгонки резисторов, а также об установках металлической 3D-печати и лазерной наплавки.

Со стороны потенциальных потребителей предложенных в рамках мероприятия решений выступил И.П. Ковалёв, главный конструктор московского филиала Научнопроизводственного центра "Промэлектроника". Кратко рассказав об истории и деятельности предприятия, докладчик отметил, что, помимо импортозамещения, существует задача унификации используемой ЭКБ. При этом имеет место недостаток номенклатуры отечественных устройств, в том числе микропроцессорных, отвечающих потребностям предприятия по производительности, энергопотреблению, а также соответствующих требованиям нормативных документов по устойчивости к внешним факторам для применения в железнодорожной технике. Докладчик призвал представителей разработчиков и производителей ЭКБ к участию в устранении этого недостатка.

О потребностях в отечественной ЭКБ для аппаратуры, применяемой ОАО “РЖД", рассказал Е.А.Гоман, главный инженер ОАО "ЭЛТЕЗА" - дочерней компании ОАО "РЖД", являющейся, по Сути, основным заказчиком компонентной базы электронной аппаратуры для российских железных до-

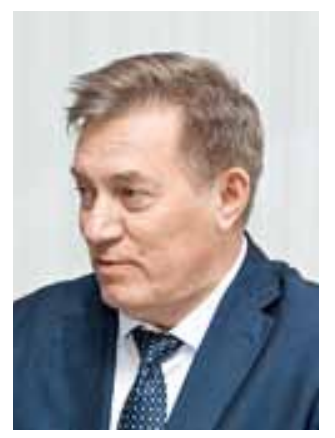
рог. Поблагодарив организато-

ров мероприятия, которое, по его словам, позволяет развеять сомнения в существовании отечественной
ЭКБ, он отметил, что в начале 2000-х годов в РЖД была заложена стратегия, направленная на переход с релейной базы на микропроцессорную. Это был ключевой шаг, который заложил основу цифровизации железных дорог в нашей стране. За прошедшее время рядом российских компаний была внедрена микропроцессорная и релейно-процессорная диспетчерская централизация почти на 500 станциях. Примерно в то же время было заложено внедрение волоконно-оптической связи, которой сейчас покрыта практически вся сеть железных дорог.

В настоящий момент, по словам докладчика, стоит задача наращивания импортонезависимости в области ЭКБ, процессоров и перехода на новый технологический уровень. По грубой оценке потребность в российской ЭКБ для замены импортной составляет у предприятия почти 1,5 млн компонентов в год, из которых на релейную аппаратуру приходится 1 млн, а остальная часть - на электронную и радиотехническую аппаратуру.

В докладе была приведена декомпозиция различных систем, узлов и блоков вплоть до типов компонентов с указанием годовой потребности. Среди них были указаны дискретные компоненты - как пассивные, так и диоды, транзисторы, варисторы ит.п., а также реле, ряд других электромеханических компонентов, оптроны, DC-DC-преобразователи и др.

Говоря о составе микропроцессорных систем управления, разработанных ОАО "ЭЛТЕЗА", докладчик подчеркнул большой опыт и высокие достигнутые результаты по локализации и импортозамещению, одной из составляющих которых является широкое применение в аппаратуре процессоров "Эльбрус".

Е.А.Гоман пригласил представителей отечественных компаний - разработчиков и производителей ЭКБ посетить предприятия ОАО «ЭЛТЕЗА» с тем, чтобы лучше познакомиться с продукцией и выявить те области, в которых было бы возможно взаимовыгодное сотрудничество, а также порекомендовал им встраиваться в имеющиеся отработанные технические решения для железнодорожного транспорта вместо того, чтобы создавать новые аппаратно-программные комплексы, что является менее эффективным и долгим путем.

Подводя итоги заседания, Е. Н. Розенберг предложил совместно с Секцией № 9 сформировать рабочуюгруппу по сбору информации и подготовке к этапу обеспечения импортонезависимости на уровне ЭКБ в аппаратуре РЖД.

«Опираясь на наше перспективное технологическое и на ваше аппаратно-конструкторское видение нужно сделать резкий шаг вперед", - отметил Е. Н. Розенберг. 